\title{
Meta
}

Journal des traducteurs

Translators' Journal

\section{Glissez, mortels...}

\section{A. Papineau-Couture}

Volume 18, numéro 3, septembre 1973

URI : https://id.erudit.org/iderudit/002425ar

DOI : https://doi.org/10.7202/002425ar

Aller au sommaire du numéro

Éditeur(s)

Les Presses de l'Université de Montréal

ISSN

0026-0452 (imprimé)

1492-1421 (numérique)

Découvrir la revue

Citer cet article

Papineau-Couture, A. (1973). Glissez, mortels... Meta, 18(3), 328-329.

https://doi.org/10.7202/002425ar

Ce document est protégé par la loi sur le droit d'auteur. L'utilisation des services d'Érudit (y compris la reproduction) est assujettie à sa politique d'utilisation que vous pouvez consulter en ligne.

https://apropos.erudit.org/fr/usagers/politique-dutilisation/
Cet article est diffusé et préservé par Érudit.

Érudit est un consortium interuniversitaire sans but lucratif composé de l’Université de Montréal, l'Université Laval et l'Université du Québec à Montréal. Il a pour mission la promotion et la valorisation de la recherche. https://www.erudit.org/fr/ 


\section{PROBLÈMES ET SOLUTIONS}

\section{GLISSEZ, MORTELS...}

Dans la Robe de sagesse, qui est une traduction de l'anglais au français par France-Marie Watkins de The Saffron Robe de T. Lobsang Rampa, et dont l'action se passe dans une lamaserie au Tibet, au cours de la visite du laboratoire de pharmacie on dit au jeune Rampa : «Regarde ceci, un produit de notre pays. De l'écorce d'orme. Un certain orme que nous appelons l'orme glissant. »

Il est évident que « orme glissant » est la traduction littérale de slippery elm, dont l'écorce est depuis longtemps employée contre l'embarras gastrique. Mais « orme glissant » est-il le nom courant ou usuel de cette espèce d'orme. Pour ma part j'en doutais fort et j'ai voulu m'en assurer.

J'étais à ce moment à la campagne et j'ai consulté les dictionnaires à ma portée. Le petit Larousse ne fournit aucun renseignement au mot «orme». Le petit Harrap et le Collegiate Webster ne font ni l'un ni l'autre la moindre mention de slippery elm soit à elm soit à slippery. De retour à Montréal j'ai consulté le Harrap complet et le Nouveau Larousse universel qui ne m'ont pas éclairé, non plus que le Robert. Le Webster International (1941) donne : «Slippery elm. A North American elm (Ulmus fulva)... Also, the fragrant mucilaginous inner bark of this tree, used as a demulcent. »

J'ai trouvé dans le bulletin $\mathrm{n}^{\circ} 61$ du ministère des Forêts du Canada, Arbres indigènes du Canada, $3^{e}$ éd., 1961 :

On connaît 18 espèces d'ormes dans l'hémisphère septentrional. Six habitent l'Amérique du Nord, dont 3, l'orme d'Amérique, l'orme rouge et l'orme de Thomas, sont indigènes au Canada central et oriental (p. 178).

Orme rouge, Ulmus umbra, Muhl.

Orme gras, orme fauve, orme roux.

L'orme rouge se reconnaît bien à son liber odorant et mucilagineux, d'où son nom anglais de stippery elm (p. 182). 

trouve :

Enfin, dans Flore laurentienne du frère Marie-Victorin, qui fait autorité, on

Ulmus fulva Michx. — orme roux - orme rouge, orme gras (slippery elm) (p. 171).

Madame Watkins aurait donc dû dire «orme roux» et non pas «orme glissant ».

Comme quoi, en traduction, on se trouve parfois sur un terrain "glissant 》 sur lequel, en s'avançant avec précaution, on finit, le plus souvent par se retrouver sur un terrain solide.

A. Papineau-Couture 